\title{
The impact of social interaction anxiety in the use of learning management system: a tentative model
}

\begin{abstract}
Learning Management System is a relatively new phenomenon and until very recently their use in University was limited, now the lecturers and the students have been push to use this system so that they have a better and improvement in learning situation. The Learning Management System is already changing the organization and delivery of higher education. The pedagogical forces that have driven the higher learning institutions to adopt and incorporate ICTs in teaching and learning include greater information access and greater communication. This concept paper is observes the impact of Learning Management System usage among university students. It is also looks at the moderating effect of Learning Management System usage between Offline Social Interaction and Social Interaction Anxiety. This research becomes a concern because a significant relationship social interaction anxiety was found between the level of problematic Internet use and social interaction anxiety, (Cem Cuhadar, 2011). The paper observes the Anxiety/Uncertainty Management (AUM) Theory, developed mainly by William Gudykunst (1995).
\end{abstract}

Keyword: Social interaction anxiety; Learning management system; E-learning 